\title{
STUDY OF DENTAL DISEASE PATTERN AND DRUG UTILIZATION EVALUATION AMONG PATIENTS VISITING DENTAL OUTPATIENT DEPARTMENT OF TERTIARY CARE CENTER \\ Ruchi Shrestha ${ }^{1,{ }^{*}}$, Sony Shakya Shrestha ${ }^{1}$, Sushmit Koju ${ }^{2}$, Manoj Humagain ${ }^{3}$ \\ ${ }^{1}$ Department of Pharmacology, Kathmandu University School of Medical Sciences, Dhulikhel, Kavrepalanchok, Nepal \\ ${ }^{2}$ Department of Oral Medicine and Radiology, Dhulikhel Hospital, Kathmandu University Hospital, Kavrepalanchok, Nepal ${ }^{3}$ Department of Periodontics, Dhulikhel Hospital, Kathmandu University Hospital, Kavrepalanchok, Nepal.
}

\author{
Received: 2 Feb, 2020 \\ Accepted: 9 Mar, 2020 \\ Published: 13 Mar, 2020 \\ Key words: Dental disease; Drug utilization; Prescrip- \\ tion; Prescribing indicators. \\ *Correspondence to: Ruchi Shrestha, Department \\ of Pharmacology, Kathmandu University School of \\ Medical Sciences, Dhulikhel, Kavrepalanchok, Nepal. \\ Email: ruchistha11@gmail.com \\ DOI:https://doi.org/10.3126/jcmc.v10i1.28064 \\ Citation \\ Shrestha R, Shrestha SS, Koju S, Humagain M. Study of \\ dental disease pattern and drug utilization evaluation \\ among patients visiting dental outpatient department \\ of tertiary care center.Journal of Chitwan Medical Col- \\ lege.2020;10(31):19-23.

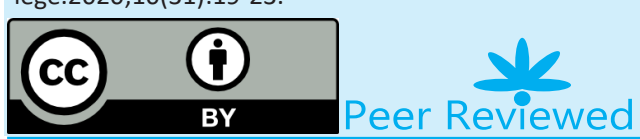

\section{INTRODUCTION}

Oral health has been an integral component of general health. ${ }^{1}$ Neglect in oral health frequently lead to serious general health problems, significant pain and interference with eating and over use of emergency room. ${ }^{2}$

Globally, oral diseases constitute a major public health problem. ${ }^{3}$ Nepal, being one of the poorest countries, the cost of dental services prohibits the majority of the Nepalese population to access those services. ${ }^{4}$ Apart from the use of dental services, drugs such as analgesics, antimicrobials, muscle relaxants and antiseptics are routinely prescribed in dental practice for many conditions. ${ }^{5}$ However, World Health Organization (WHO) estimates that more than half of all medicines are inappropriately prescribed, dispensed or sold. Tackling the issue of irrational medicine use is considered to be essential not only to improve healthcare delivery towards ensuring patient safety, but also to allow optimal utilization of resources. ${ }^{6}$

The aim of this study was to find common dental disease pattern and to know drug utilization pattern among patients visiting Dental Outpatient Department (OPD) of Dhulikhel Hospital-Kathmandu University Hospital (DH-KUH).

\section{METHODS}

A descriptive, cross sectional study was conducted in Dental OPD of DH-KUH, Kavrepalanchok, Nepal from October 2018 to January 2019. Ethical approval was obtained from the Institutional Review Committee of Kathmandu University School of Medical Sciences (124/18). Prescriptions of 240 patients visiting Dental OPD and receiving medications irrespective of their age, sex and diagnosis were included in the study. Informed verbal consent was taken from each participant prior to data collection.

Convenience sampling was used. Data was collected from prescriptions of patients visiting Dental OPD of DH-KUH and evaluated for demographic parameters, diagnosis, drugs prescribed including its dose, route of administration, frequency and duration of treatment. Number of drugs per prescription, prescription by generic/trade name, drug from National List of Essential Medicines (NLEM)-Nepal, monotherapy/Fixed Dose Combination (FDC) were also recorded.

Statistical package for Social Sciences (SPSS) version 20 was used for data entry and analysis. Descriptive tests were used and results were expressed as frequency and percentage. 


\section{RESULTS}

Prescriptions of 240 patients were analyzed during the study period. Among them, 109 (43.6\%) were male, and 131 (52.4\%) were female. Mean age of study participants was $34.03 \pm 1.70$ years. Diagnosis of only the condition for which drugs were given was recorded. Pulpitis was the most common diagnosis 54 (22.5\%) followed by periapical abscess 34 (14.16\%) (Table 1 ).

Table 1: Dental disease pattern

\begin{tabular}{|l|c|}
\hline Dental disease & $\mathbf{n}(\%)$ \\
\hline Pulpitis & $54(22.5)$ \\
\hline Periapical abscess & $34(14.16)$ \\
\hline Impaction/pericoronitis & $29(12.08)$ \\
\hline Chronic generalized gingivitis & $22(9.17)$ \\
\hline Chronic generalized periodontitis & $19(7.92)$ \\
\hline Malocclusion & $18(7.50)$ \\
\hline Traumatic ulcer & $10(4.17)$ \\
\hline Dentine sensitivity & $9(3.75)$ \\
\hline Myalgia & $8(3.33)$ \\
\hline Physiological mobility & $5(2.08)$ \\
\hline Trauma & $4(1.67)$ \\
\hline Apical periodontitis & $4(1.67)$ \\
\hline Others* & $24(10)$ \\
\hline Total & $240(100)$ \\
\hline
\end{tabular}

*allergic stomatitis, oral candidiasis, space infection, chemical burn, herpes labialis, lichen planus, leucoplakia

Total 411 drugs were prescribed in 240 prescriptions. Among them, 166 (40.38\%) were analgesic agents, 116 (28.22\%) antibiotics (Table 2).

\section{Table 2: Prescribed group of drugs}

\begin{tabular}{|l|c|}
\hline Drug group & $\mathbf{n}(\%)$ \\
\hline Analgesics & $166(40.38))$ \\
\hline Antibiotics & $116(28.22)$ \\
\hline Topical agents & $93(22.62)$ \\
\hline Gastroprotective agents & $16(3.89)$ \\
\hline Muscle relaxants & $10(2.43)$ \\
\hline Antihistaminics & $3(0.73)$ \\
\hline Multiviatmins & $3(0.73)$ \\
\hline Enzymes & $2(0.48)$ \\
\hline Antifungal & $2(0.48)$ \\
\hline Total & $411(100)$ \\
\hline
\end{tabular}

Combination of paracetamol and ibuprofen was the most commonly prescribed analgesics 133 (80.12\%). Similarly, combination of amoxicillin and clavulanic acid was the most commonly prescribed antibiotics 51 (43.97\%). Among all the topical agents, chlorhexidine gluconate $0.2 \%$ was the most commonly prescribed mouthwash 33 (35.48\%) (Table 3).
Table 3: Most commonly prescribed drugs

\begin{tabular}{|l|c|}
\hline Drugs & $\mathrm{n}(\%)$ \\
\hline Analgesics & $133(80.12)$ \\
\hline Paracetamol+ibuprofen & $18(10.84)$ \\
\hline Paracetamol & $10(6.02)$ \\
\hline Ibuprofen & $2(1.20)$ \\
\hline Aceclofenac & $2(1.20)$ \\
\hline Tramadol & $1(0.60)$ \\
\hline Codeine+paracetamol & Total: $166(100)$ \\
\hline \multicolumn{2}{|c|}{} \\
\hline Antibiotics & $51(43.97)$ \\
\hline Amoxicillin+clavulanic acid & $35(30.17)$ \\
\hline Amoxicillin & $26(22.41)$ \\
\hline Metronidazole & $3(2.57)$ \\
\hline Doxycycline & $1(0.86)$ \\
\hline Phenoxymethyl penicillin & Total: $116(100)$ \\
\hline \multicolumn{2}{|l|}{} \\
\hline Topical agents & $33(35.48)$ \\
\hline Chlorhexidine gluconate & $26(27.96)$ \\
\hline Deltagel/qudragel, hexigel, mucopain & $11(11.83)$ \\
\hline Diclofenac gel & $10(10.75)$ \\
\hline Desensitizing paste & $9(9.68)$ \\
\hline Moutherwash (other than CHX) & $4(4.30)$ \\
\hline Others topical gel* & Total: 93(100) \\
\hline &
\end{tabular}

* triamcinolone, acyclovir, polysporin

Out of all drugs prescribed, FDC was given for 194 (47.20\%). Combination of paracetamol and ibuprofen 129 (66.49\%) and amoxicillin with clavulanic acid 50 (25.77\%) was most commonly prescribed FDC (Table 4).

\section{Table 4: Most commonly prescribed FDC}

\begin{tabular}{|l|c|}
\hline FDC & $\mathbf{n}(\%)$ \\
\hline Paracetamol+ibuprofen & $129(66.49)$ \\
\hline Amoxicillin+clavulanic acid & $50(25.77)$ \\
\hline Chlorzoxazone+paracetamol & $9(4.65)$ \\
\hline Multivitamins & $3(1.54)$ \\
\hline Trypsin+chemotrysin & $2(1.03)$ \\
\hline Codeine+paracetamol & $1(0.51)$ \\
\hline Total & $194(100)$ \\
\hline
\end{tabular}

Table 5: Data on prescribing pattern in Dental OPD

\begin{tabular}{|l|c|}
\hline Indicators & $\mathbf{n}(\%)$ \\
\hline Total number of prescriptions & 240 \\
\hline Total number of drugs prescribed & 411 \\
\hline Average number of drugs per prescription & 1.71 \\
\hline Prescriptions of drugs by generic name & $260(63.26)$ \\
\hline $\begin{array}{l}\text { Prescriptions of drugs containing encoun- } \\
\text { ters with antibiotics }\end{array}$ & $90(37.50)$ \\
\hline $\begin{array}{l}\text { Prescriptions of drugs from National List of } \\
\text { Essential Medicines-Nepal }\end{array}$ & 133 (32.36) \\
\hline
\end{tabular}


Data on prescribing parameters are summarized in Table 5. Out of 240 prescriptions, $123(51.25 \%)$ patients received 1 medication, 75 (31.25\%) were given two medications, 32 (13.33\%) were given three medications and $10(4.17 \%)$ patient more than three medications.

\section{DISCUSSION}

Oral diseases are among the highest prevalent health conditions affecting 3.5 billion people worldwide. ${ }^{7}$ Dental caries and periodontal disease are the most important global oral health burdens. Other burdens include oral cancer, oral mucosal lesions, maxillofacial and dental trauma, developmental disorders and teeth wear. ${ }^{3}$ Proper diagnosis of a dental condition and its management with dental procedure and use of drugs plays a pivotal role in dental care. ${ }^{5}$ Irrational drug use is prevalent, especially in the developing countries, reasons being irrational prescribing, dispensing and administration of medications. Drug utilization studies seek to monitor, evaluate, and suggest modifications in prescribing practices with the aim of making medical care rational and cost effective and may be useful in maximum utilization of resources. ${ }^{8}$

This study was carried out to evaluate the pattern of presentation of oral conditions and drug utilization in patients who visited the dental OPD of DH- KUH. In this present study, pulpitis was the most common presentation (22.5\%) for which patients were given medications, followed by periapical abscess $(14.16 \%)$ and pericoronitis $(12.08 \%)$. The result was similar to the national studies ${ }^{9,10}$ in which dental caries (37\%) and chronic irreversible pulpitis (28\%) was the most common diagnosis. The data was also similar to international study ${ }^{11}$ where dental caries and its sequelae (73.1\%) was the most common diagnosis among patients seeking dental treatment. Dental caries, the most prevalent oral diseases, result from the activity of bacterial plaque. Fermentation of sucrose and other non-milk extrinsic sugars to lactic and other acids causes tooth decalcification and proteolysis, resulting in cavitation and caries. Untreated caries can progress through the dentine to the pulp, leading to pulpitis and necrosis of the pulp eventually. Inflammation can then spread around the tooth apex, eventually forming an abscess, granuloma, or cyst. ${ }^{12}$

Analgesics (40.38\%) followed by antibiotics (28.22\%) were the most commonly prescribed drug group. The results were similar to the study where analgesics and antibiotics were frequently group of prescribed drugs. ${ }^{9}$ Odontogenic pain due to periapical and pulpal disease is considered as the most frequent pain in dental health settings. The majority of clinical indications of analgesic prescriptions relate to the treatment of acute and chronic dental pain and adjunctive intraoperative and postoperative pain. ${ }^{13}$ Diseases of the dental pulp and periapical tissue are caused by microorganisms; however, not all cases of endodontically involved teeth require the administration of systemic antibiotics. The majority of endodontic infections do not require systemic antibiotic therapy when the cause of the infection has been properly managed by complete debridement of the pulp. ${ }^{14}$
Among the antibiotics, combination of amoxicillin and clavulanic acid was the most commonly prescribed drugs (43.97\%), followed by amoxicillin (30.17\%) and metronidazole (22.41\%). This was similar to the study conducted by Roda et $\mathrm{al}^{15}$ in which combination of amoxicillin and clavulanic acid was the most common antibiotics prescribed, whereas in the study done by Sharma et al, ${ }^{16}$ amoxicillin alone was the most commonly prescribed antibiotics in dental practice. Since control and prevention of infection is an important factor in outpatient dentistry and the most common pathogens are gram-positive bacteria, so the use of systemic antibiotics like amoxicillin is justified. ${ }^{17}$ The inactivation of amoxicillin by beta-lactamases can be circumvented by the addition of clavulanic acid, a betalactamases inhibitor. But according to the retrospective chart study ${ }^{18}$ which included different studies, reported there was no difference between amoxicillin and combination of amoxicillin with clavulanic acid combination in treating infections successfully. Antimicrobials are invaluable adjuncts in the management of orofacial infections. Although they are not a substitute for definitive treatment, their judicious use can shorten infection periods and minimize associated risks. ${ }^{19}$ However, overuse of antibiotics leading to antibiotics resistance should also be kept under consideration.

Out of all analgesics prescribed, $80.12 \%$ of analgesics was given as combination of ibuprofen and paracetamol which was in higher level when compared to the study, ${ }^{16}$ where the same combination was used in $42.7 \%$. Combining these two nonsteroidal anti-inflammatory drugs does not improve the efficacy of treatment as they act on the same enzyme and offer no synergism. Such irrational combinations expose patients to unnecessary risk of adverse drug reactions and needlessly increase the cost of therapy. ${ }^{20}$

In this study, chlorhexidine gluconate $0.2 \%$ was the most commonly prescribed topical agent $(35.48 \%)$ which was similar to study ${ }^{21}$ where antimicrobial effect of chlorhexidine was more when compared to other mouthwashes. Chlorhexidine is the most effective and most thoroughly tested antiplaque and antigingivitis agent known till today. It is effective in preventing and controlling plaque formation, breaking up existing plaque, and inhibiting and reducing the development of gingivitis. ${ }^{22}$

The mean number of drugs prescribed in the present study was 1.71 per prescription. Studies suggest this value ranging from 1.3 as reported by a study conducted in twelve developing countries ${ }^{23}$ to 4.51 as reported by a study conducted at Southeast Asian country. ${ }^{24}$ In this study, percentage of encounters with an antibiotics prescribed was $37.50 \%$. According to the study, ${ }^{23}$ percentage of encounters with antibiotic prescription ranged from $23 \%$ in Bangladesh to $63 \%$ in Sudan. Overuse of antibiotics causes adverse events, contributes to antibiotic resistance, and unnecessary treatment costs. ${ }^{25}$

Percentage of drugs prescribed by generic name was found only in $63.26 \%$, out of all drugs prescribed. This data differed from the national study ${ }^{10}$ where drug prescription by generic name was nil and international study ${ }^{26}$ where prescription of 
drugs by generic name was high (93.3\%). Use of generic name should be encouraged in developing countries like Nepal to make therapy cost-effective without compromising quality, limit commercial influence by pharmaceutical companies and reduce the potential for prescribing errors. ${ }^{27}$

In this study, drugs prescribed from National NLEM-Nepal was $32.36 \%$, which is very less as compared to study done in Western Nepal which reported $75.6 \%$ on the same parameter. ${ }^{28}$ Prescribing from EML, especially in developing countries like Nepal, is important as drugs are selected with according to local disease prevalence and they promote the availability, accessibility, affordability, quality, safety and rational use of medicines. ${ }^{29}$

Out of all drugs prescribed, FDC was prescribed in $47.20 \%$. Combination of paracetamol with ibuprofen was given in $66.49 \%$ and combination of amoxicillin with clavulanic acid was given in $25.77 \%$. It is widely accepted that most drugs should be formulated as single compound. FDC products are acceptable only when the dosage of each ingredient meets the requirement of a defined population group and when the combination has a proven advantage over single compound administered separately in therapeutic effect, safety or compliance. Irrational FDC expose patients to unnecessary risk of adverse drug reactions and also impose an unnecessary financial burden on consumers. ${ }^{30}$

\section{REFERENCES:}

1. Kwan SY PP, Pine CM, Borutta A. Health-promoting schools: an opportunity for oral health promotion. Bull World Health Organ. 2005;83(9):67785. https://www.ncbi.nlm.nih.gov/pubmed/16211159, [PMID]

2. Coye MJ, Edmunds M. America's children: Health insurance and access to care: National Academies Press; 1998. [PMID]

3. Auluck A. Oral health of poor people in rural areas of developing countries. J Can Dent Assoc. 2005;71(10):753-5. [LINK]

4. Yee R, Mishra P. Nepal national oral health 'pathfinder' survey 2004: Ministry of Health, HMG Nepal 2004. [LINK]

5. Abbott PV, Dean D. Medical management of dental and oral pain. Aust Prescr. 2007;30:77-9. [LINK]

6. Creese A, Gasman N, Mariko M. The World Medicines Situation. Geneva: World Health Organization, 2004. [LINK]

7. Kassebaum N, Smith A, Bernabé E, Fleming T, Reynolds A, Vos T, et al. Global, regional, and national prevalence, incidence, and disability adjusted life years for oral conditions for 195 countries, 1990-2015: a systematic analysis for the global burden of diseases, injuries, and risk factors. J Dent Res.2017;96(4):380-7. [DOI]

8. Enato EF, Chima IE. Evaluation of drug utilization patterns and patient care practices. West African Journal of Pharmacy. 2011;22(1);36-41. [DOI]

9. Paudel K. Drug therapy in dental out patients. J Nepal Dent Assoc. 2010;11(2):126-30. [DOI]

10. Rauniyar GP SM, Das BP, Nagarani MA. A prospective study of dental disease pattern and drug utilization at the dental department of a tertiary care teaching hospital in Eastern Nepal. J Nepal Med Assoc. 2003;40(137):1-5. [DOI]
The study was conducted in only one center with small sample size, hence the result cannot be generalized. Multicentric studies with large sample size are required to know the complete pattern of dental disease distribution and evaluation of drug utilization used for treatment of dental diseases. Convenience sampling method was used, which could have led to selection bias of research participants. This limitation could have been prevented by using random sampling.

\section{CONCLUSIONS}

This study gave us an overall pattern of drug use in Dental OPD of DH-KUH. Drug utilization with brand names and FDC were frequent. The prescribing practices in this study are not satisfactory, as suggested by over prescription of antibiotics and lack of awareness of NELM-Nepal. It is important to create awareness about the rational use of drugs among dental doctors, the importance of prescribing drugs with generic names and avoidance of FDC in unnecessary cases to increase cost-effectiveness and decrease adverse drug reactions of medications.

\section{ACKNOWLEDGEMENTS}

The authors would like to thank all the study participants and dental staffs.

\section{CONFLICT OF INTEREST: None}

\section{FINANCIAL DISCLOSURE: None}

11. Taiwo OA, Soyele OO, Ndubuizu GU. Pattern of utilization of dental services at federal medical centre, Katsina, Northwest Nigeria. Sahel Med J. 2014;17(3):108. [DOI]

12. Holt R, Roberts G, Scully C. Dental damage, sequelae, and prevention. BMJ. 2000;320(7251):1717-9. [DOI]

13. Krasniqi S, Daci A. Analgesics Use in Dentistry. Pharmacology, Toxicology and Pharmaceutical Science - Pain Relief - From Analgesics to Alternative Therapies. 2017. 111-39. [LINK]

14. Maslamani M, Sedeqi F. Antibiotic and Analgesic Prescription Patterns among Dentists or Management of Dental Pain and Infection during Endodontic Treatment. Med Princ Pract. 2018;27(1):66-72. [PMID]

15. Roda RP, Bagan JV, Bielsa JS, Pastor EC. Antibiotic use in dental practice. A review. Med Oral Patol Oral Cir Bucal. 2007;12(3): E 186-92. [PMID]

16. Sharma M, Tandon S, Chugh T, Sharma S, PS P, Aggarwal V, et al. Drug abuse in paediatric dentistry: a cross-sectional study. J Clin Diagn Res. 2014;8(3):205-7. [DOI]

17. Tenenbaum H, Jehl F, Gallion C, Dahan M. Amoxicillin and clavulanic acid concentrations in gingival crevicular fluid. J Clin Periodontol. 1997;24(11):804-7. [DOI]

18. Esen A. The effects of amoxicillin with or without clavulanic acid on the postoperative complaints after third molar surgery: a retrospective chart analysis. J Istanb Univ Fac Dent. 2017;51(2):1-6. [DOI]

19. Sandor GK, Low DE, Judd PL, Davidson RJ. Antimicrobial treatment options in the management of odontogenic infections. J Can Dent Assoc. 1998;64(7):508-14. [PMID]

20. Burke A, Smyth E, FitzGerald GA. Analgesic-antipyretic agents; Pharmacotherapy of gout. In: Brunton LL, Lazo JS, Parker KL, editors. Goodman and Gillman's Pharmacological basis of Therapeutics, 11th edition. New York: McGraw-Hill;2006:671-715. [LINK] 
21. Rosin M, Welk A, Kocher T, Majic-Todt A, Kramer A, Pitten F. The effect of a polyhexamethylene biguanide mouthrinse compared to an essential oil rinse and a chlorhexidine rinse on bacterial counts and 4-day plaque regrowth. J Clin Periodontol. 2002;29(5):392-9. [DOI]

22. Lang N, Brecx MC. Chlorhexidine digluconate-an agent for chemical plaque control and prevention of gingival inflammation. J Periodontal Res. 1986;21:74-89. [DOI]

23. Hogerzeil HV, Ross-Degnan D, Laing R, Ofori-Adjei D, Santoso B, Chowdhury $A A$, et al. Field tests for rational drug use in twelve developing countries. The Lancet. 1993;342(8884):1408-10. [PMID]

24. Das N, Khan A, Badini Z, Baloch H, Parkash J. Prescribing practices of consultants at Karachi, Pakistan. J Pak Med Assoc. 2001;51(2):74-7. [PMID]

25. Llor C, Bjerrum L. Antimicrobial resistance: risk associated with antibiotic overuse and initiatives to reduce the problem. Therapeutic advances in drug safety. 2014 Dec;5(6):229-41. [DOI]
26. Demeke B, Molla F, Assen A, Melkam W, Abrha S, Masresha B, et al. Evaluation of drugs utilization pattern using WHO prescribing indicators in Ayder referral hospital, Northern Ethiopia. IJPSR. 2015;6(2):343-7. [DOI]

27. Steinman MA, Chren M-M, Landefeld CS. What's in a name? Use of brand versus generic drug names in United States outpatient practice. J Gen Intern Med. 2007;22(5):645-8. [DOI]

28. Rana M, Shankar P, Dubey A, Mishra P, Subish P, Bhaskar PV. Drug Utilization with special Reference to Antimicrobials in a Sub-health post in Western. J Nepal Health Res Counc. 2005;3(2):65-9. [DOI]

29. Hogerzeil HV. The concept of essential medicines: lessons for rich countries. BMJ. 2004;329(7475):1169-72. [https://www.ncbi.nlm.nih.gov/pu bmed/15539676], [DOI]

30. Gautam CS, Saha L. Fixed dose drug combinations (FDCs): rational or irrational: a view point. Br J Clin Pharmacol. 2008;65(5):795-6. [LINK] 